\title{
Linked Open Data for Taxonomic Databases: The Nordic/Baltic implementation
}

\author{
Johan Liljeblad ${ }^{\ddagger}$, Tapani Lahti ${ }^{\S}$ \\ ‡ Swedish Species Information Centre, Uppsala, Sweden \\ $\S$ University of Helsinki, Helsinki, Finland
}

Corresponding author: Johan Liljeblad (cynips@gmail.com)

Received: 14 Jun 2019 | Published: 21 Jun 2019

Citation: Liljeblad J, Lahti T (2019) Linked Open Data for Taxonomic Databases: The Nordic/Baltic implementation. Biodiversity Information Science and Standards 3: e37332. https://doi.org/10.3897/biss.3.37332

\begin{abstract}
Starting with Finland and Sweden and a subset of taxonomic groups, the Nordic/Baltic countries are connecting national checklists using Linked Open Data standards (Auer et al. 2007) and agreed vocabularies. We use HTTP Uniform Resource Identifiers as globally unique, persistent identifiers for taxon concepts (Chawuthai et al. 2013). Currently, we provide both human-readable $(\mathrm{html})$ and machine-readable $(\mathrm{xml})$ responses for client requests via a central checklist, TAXONID.ORG, which in itself needs to be managed. However, we hope this can be replaced by Catalogue of Life Plus in a not too distant future. While initially exchanging taxonomic information, our goal is ultimately to share information also on genetics, images and traits as well as conservation status and observations in a standardized way. The work is part of the NeIC DeepDive project which is funded by the Nordic e-Infrastructure Collaboration (neic.no/deepdive). The vision is to establish a regional infrastructure network consisting of Nordic and Baltic data centers and information systems and to provide seamlessly operating regional data services, tools, and virtual laboratories.
\end{abstract}

\section{Keywords}

checklist, identifier, taxon circumscription, matching, linking 


\section{Presenting author}

Johan Liljeblad

\section{Presented at}

Biodiversity_Next 2019

\section{References}

- $\quad$ Auer S, Bizer C, Kobilarov G, Lehmann J, Cyganiak R, Ives Z (2007) DBpedia: A Nucleus for a Web of Open Data. The Semantic Web 4825: 722-735. [In English]. https:// doi.org/10.1007/978-3-540-76298-0 52

- $\quad$ Chawuthai R, Takeda H, Wuwongse V, Jinbo U (2013) A logical model for taxonomic concepts for expanding knowledge using Linked Open Data. Semantics for Biodiversity (S4BioDiv 2013) 9-16. [In English]. URL: https://hal-lirmm.ccsd.cnrs.fr/lirmm-00831757/ document\#page $=10$ 